Open Access

\title{
Prevalence of antenatal depression and associated factors among pregnant women in Addis Ababa, Ethiopia: a cross-sectional study
}

\author{
Abera Biratu ${ }^{1}$ and Demewoz Haile 2* $^{*}$
}

\begin{abstract}
Background: The World Health Organization identifies depressive disorders as the second leading cause of global disease burden by 2020. However, there is a paucity of studies which examined the associated factors of antenatal depression in low-income countries. This study aimed to determine the prevalence of antenatal depression and associated factors among pregnant women in Addis Ababa, Ethiopia.
\end{abstract}

Methods: A cross-sectional study was employed among 393 pregnant women attending antenatal care service in Addis Ababa public health centers, Ethiopia from April 12-26, 2012. The Edinburgh Postnatal Depression Scale (EPDS) was used to detect depressive symptoms. Descriptive statistics and logistic regression were used in the statistical analysis.

Results: Prevalence of antenatal depression was $24.94 \%$ (95 \% Cl: 20.85-29.30\%). In the final multivariable model, those pregnant women who have previous history of depression were nearly three times at higher odds of having antenatal depression as compared to pregnant women who have no history of depression [AOR $=2.57(95 \% \mathrm{Cl}$ : 1.48-4.48 )]. Those pregnant women having unplanned pregnancy were nearly three times at higher odds to develop depression as compared to pregnant women whose pregnancy was planned [AOR $=2.78(95 \% \mathrm{Cl}: 1.59-4.85)]$. The odd of developing antenatal depression was $89 \%$ higher in those pregnant women who experienced lack of baby's father support [AOR $=1.89(95 \% \mathrm{Cl}:$ 1.06-3.36)]. Education level, community's support, and partner's feeling on current pregnancy were not significantly associated factors with antenatal depression in the final multivariable model.

Conclusion: Although clinical confirmation for antenatal depression is not conducted, one quarter of the pregnant women attending antenatal care were depressed in Addis Ababa based on EPDS. Unplanned pregnancy, experiencing lack of baby's father support and previous history of depression were factors independently associated with antenatal depression. Promotion of family planning and integration of mental health service with existing maternal health care as well as strengthening the referral system among public health centers were the recalled interventions to prevent antenatal depression in Addis Ababa Public Health Centers.

Keywords: Antenatal care, Depression, Maternal health, Mental health, Low income countries, Ethiopia

\footnotetext{
* Correspondence: demewozhaile@yahoo.com

${ }^{2}$ Department of Reproductive Health, College of Medicine and Health

sciences, Bahir Dar University, P.Box 79, Bahir Dar, Ethiopia

Full list of author information is available at the end of the article
}

C Biomed Central (c) 2015 Biratu and Haile. Open Access This article is distributed under the terms of the Creative Commons Attribution 4.0 International License (http://creativecommons.org/licenses/by/4.0/), which permits unrestricted use, distribution, and reproduction in any medium, provided you give appropriate credit to the original author(s) and the source, provide a link to the Creative Commons license, and indicate if changes were made. The Creative Commons Public Domain Dedication waiver (http://creativecommons.org/publicdomain/zero/1.0/) applies to the data made available in this article, unless otherwise stated. 


\section{Introduction}

Depression is among the most prevalent psychiatric disorders affecting women [1,2]. Depressive disorders are predicted to be the second leading cause of global disability burden by 2020 [2]. The risk of depression increased significantly during pregnancy $[3,4]$ and clinically significant depressive symptoms are common in mid and late trimesters [4]. Several studies have reported that depressive symptoms are more frequent during pregnancy than during the postpartum period $[3,5-7]$.

A meta-analysis study done in the developed countries showed that the prevalence rates of depression (95\% confidence interval, CIs) were $7.4 \%(2.2-12.6 \%), 12.8 \%$ (10.7-14.8\%), and $12.0 \%(7.4-16.7 \%)$ for the first, second, and third trimesters, respectively [7]. A systematic review from low- and lower-middle-income countries revealed that the mean weighted prevalence of antenatal common mental disorders was 15.6 \% (95 \% CI: 15.4$15.9 \%$ ) [8]. High prevalence of antenatal depression has been reported from developing countries i.e. $29 \%$ in Bangladesh [9], $25 \%$ in Pakistan [10], $20.2 \%$ in Brazil [11], 39 \% in South Africa Cape Town [12], 38.5 \% in South Africa KwaZulu-Natal [13] and $39.5 \%$, in Tanzania [14].

Depressive symptoms during pregnancy may have devastating consequences, not only for the women, but also for the child and family [15]. Depression during pregnancy negatively influences social adjustment and marital relationships [16, 17]. It affects also the mother-infant interaction through its influences on the occurrence of postnatal depression [18, 19]. Studies also showed that there is a significant associations between antenatal depression and poor infant outcomes (low birth weight, preterm delivery or both, fetal growth restriction) in low [20-22] and middleincome countries [23].

Pregnant women with depression are also more likely to suffer from obstetrical complications such as preeclampsia [24-26]. Despite the fact that antenatal depression is a common condition with serious consequences, only a few studies have been conducted in lowincome countries like Ethiopia. The first study was a validation study of Edinburgh Postnatal Depression Scale (EDPS) on perinatal mental disorder among rural women. That study found a limited validity of EDPS among rural women [27]. However this tool was again tried among postnatal women in urban residents which showed a good reliability and validity [28]. A more recent study conducted on Southwestern Ethiopia found that the prevalence of depressive symptoms during pregnancy was $19.9 \%$ (95 \% CI, 16.8-23.1), using EPDS cut off point of 13 and above [29]. The small number of studies conducted in Ethiopia showed that there is a paucity of evidences on antenatal depression to design appropriate intervention. Thus this study aimed to determine the prevalence of antenatal depression and identify factors associated with antenatal depression in Addis Ababa, Ethiopia.

\section{Methods}

\section{Study setting and design}

This study was conducted in Addis Ababa which is the capital city of Ethiopia. The population of Addis Ababa was $2,738,248$ in 2007 , of which $52.4 \%$ are females, and women between 15 and 49 years of age constitute $34.6 \%$ [30]. There were 26 health centers which are eligible for this study. Maternal health services are free of charge in Ethiopia at Public health institutions including those Public Health centers included in this study. Antenatal care is provided in all public health centers of Addis Ababa without any cost like other maternal health services. An institutional based cross sectional study design was employed in six selected public health centers in Addis Ababa. The data collection period was from April 12-26, 2012.

\section{Sample size and sampling procedure}

The sample size of 422 was determined based on the formula for a single population proportion by assuming a prevalence of antenatal depression of $50 \%$, confidence level $95 \%$, margin of error 5 and $10 \%$ for non-response rate. Six public health centers, namely Addis Ketema, Bole, Gulele, Kotebe, Meshualekia, and Yeka, were selected randomly from the 26 health centers that are under the Addis Ababa Bureau of Health. All consenting women attending for antenatal care during the study period in each health center were taken into the study until the sample size was reached. Any apparently healthy pregnant women at any age of gestation who had come to those health institutions during the study period were included in the study. However pregnant women who came for the treatment of any medical diseases including trauma related illness were excluded from the study by assuming that the medical illness they were experiencing during the data collection might affect their mental status. Pregnant women who unable to hear or speak were also excluded from the study. Pregnant women with clinically identified HIV infection, diabetes mellitus, and tuberculosis who were in care during the time of data collection were excluded from the study.

\section{Measurements}

The Edinburgh Postnatal Depression Scale (EPDS) [31] has been used to detect depressive symptoms. The EPDS is a 10 item questionnaire, scored from 0 up to 3 (higher score indicating more depressive symptoms), that has been validated for detecting depression in ante partum and postpartum samples in many countries. The 
instrument was validated in public health centers in Addis Ababa for postpartum use and showed sensitivity of $84.6 \%$ and specificity of $77.0 \%$ at the cutoff score $7 / 8$ [28]. The cutoff point of EDPS among pregnant women is usually higher than postpartum women [32]. Like other similar studies conducted abroad and in Ethiopia, we used EPDS cutoff point of 13 to identify pregnant women with depressive symptom [29, 33]. Those pregnant women who scored 13 and above were categorized as depressed women while pregnant women who scored below 13 were considered as non depressed women [29]. Partner's feeling on current pregnancy can be defined as pregnant women feeling about the feeling of her partners regarding the current pregnancy. It was measured by asking the pregnant women to rate whether her partner feels happy or not happy on the current pregnancy. Baby's father support was measured by asking the pregnant women feeling about the partners support to the health of the fetus and continuation of the pregnancy. Community support is measured by asking the pregnant women feeling about the emotional support of the community. The explanatory variables: baby's father support (poor vs good), partner's feeling on current pregnancy (happy vs unhappy), community support (poor vs good), and substance use history (yes vs no) were collected by a structured questionnaire. Socio-demographic characteristics and obstetric variables: trimester (first, second and third), having previous pregnancy (yes vs no), previous pregnancy \& labor complication (yes vs no), previous history of stillbirth (yes vs no), previous history of abortion (yes vs no), is the current pregnancy planned (yes vs no), previous ANC follow up (no follow up, sometimes, regular) and current pregnancy complication (yes vs no) were also collected by a structured questionnaire. The conceptual framework is presented in Fig. 1.

\section{Data collection tool and process}

The same Amharic version of Edinburgh Postnatal Depression Scale which has ten items was used as the previous validation study [27]. The questionnaire was prepared first in English then translated in to Amharic and back to English to check for consistency by two independent bilingual Ethiopian final years mental health postgraduate students. The Amharic version of this questionnaire was also used to collect the data. The questionnaire was pretested among pregnant women attending ANC clinic at Arada Health Center. Data were collected by trained, female and experienced diploma nurse holders

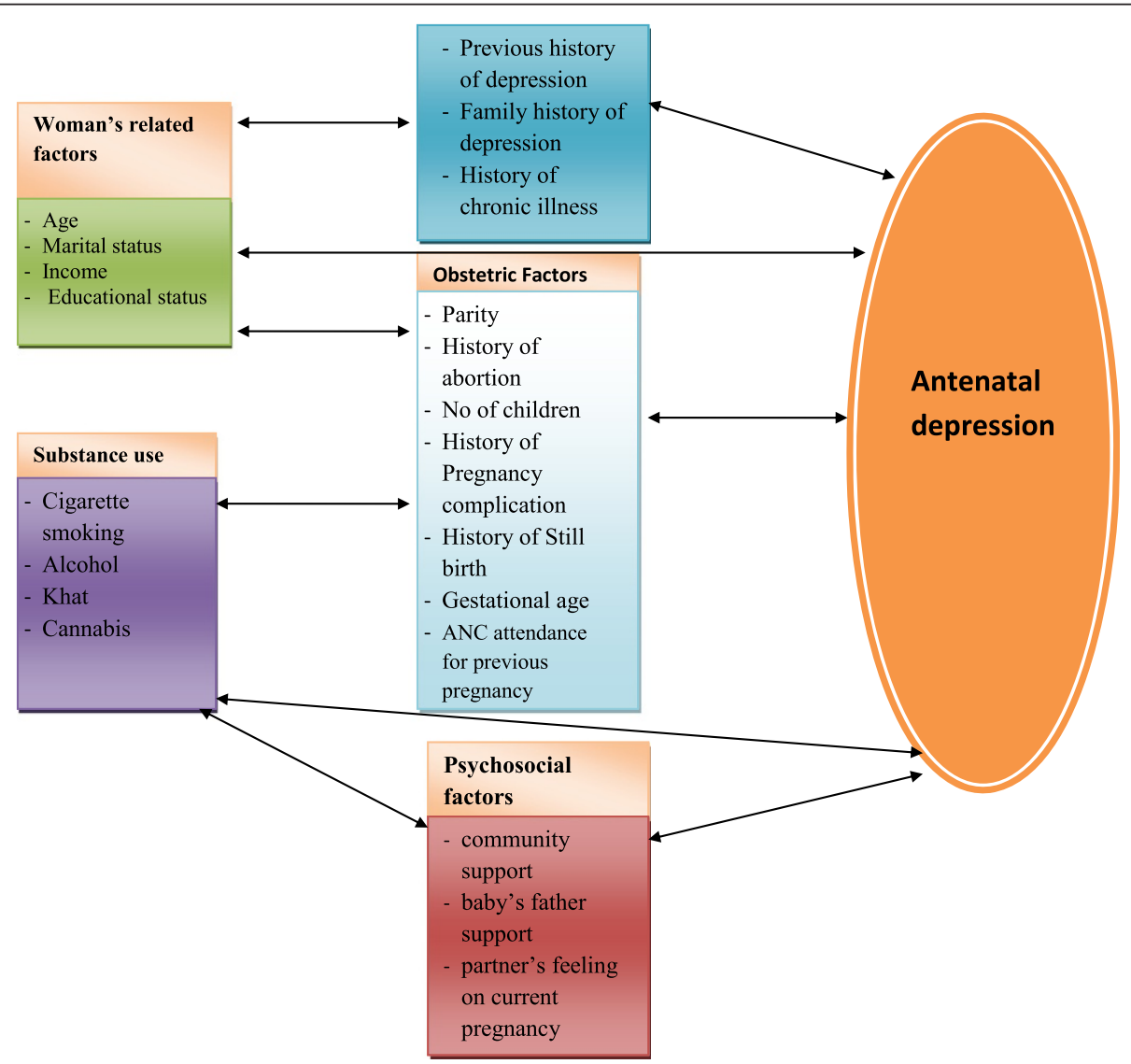

Fig. 1 Conceptual framework of antenatal depression and associated factors 
with a close supervision of the principal investigator and trained supervisors. Two days training was given to the data collectors on the data collection tool, interview technique, eligible study subjects, sampling techniques and consent.

\section{Statistical analysis}

The coded data was checked, cleaned by entering into Epi Info and exported into Statistical Package for the Social Sciences (SPSS window version 16, Chicago Illinois) for analysis. Descriptive statistics was employed to estimate the prevalence of antenatal depression. Bivariate analyses (binary logistic regression) were carried out between the predictors and antenatal depression. Using significant variables $(P<0.05)$ from binary logistic regression models, a multivariable logistic regression model was fitted to identify the independent predictors of antenatal depression. The strength of association was measured by odds ratios with $95 \%$ confidence intervals. All tests were two sided and statistical significance was declared at $P<0.05$.

\section{Ethical consideration}

Ethical clearance was obtained from Institutional Review Board (IRB) of University of Gondar. Letter of permission was obtained from Addis Ababa Health Bureau. All Antenatal clinic attending women were approached and participants who gave written consent were interviewed. All the study participants were with age greater than 18 years. The interview was conducted in a separate room in the antenatal clinic. Personal identifying details were not recorded. Participants identified with depressive symptoms were advised to visit the psychiatric clinic for better evaluation and treatment.

\section{Results}

\section{Socio-demographic characteristics}

The response rate for this study was $93.13 \%$. The mean age of the respondent was 25.27 years (Standard Deviation, $\mathrm{SD}=4.335)$. The age of the respondents ranges from 18-38 years. Three hundred fifty four $(90.1 \%)$ of the women were married. Almost 337 (85.7 \%) of the women had attended formal education. Majority of the respondents were orthodox by religion $279(71 \%)$ and Amhara by ethnic group 195 (49.6\%). Majority of the respondents 277 (70.5 \%) had a monthly income of above 500 Ethiopian birr (ETB) (Table 1).

\section{Obstetric and clinical characteristics}

Most of the pregnant women (366; $93.9 \%$ ) were in either their second or third trimester at the time of the study. Near to half of the pregnant women (191; $48.6 \%)$ were primigravidas. One tenth of the pregnant women had a previous obstetric complication and $11(2.8 \%)$ of
Table 1 Socio-demographic characteristics of pregnant women's attending antenatal care at public health centers in Addis Ababa, $2012(n=393)$

\begin{tabular}{|c|c|c|}
\hline & Frequency & Percentage (\%) \\
\hline \multicolumn{3}{|l|}{ Maternal age } \\
\hline$<20$ Years & 34 & 8.7 \\
\hline $20-24$ Years & 138 & 35.1 \\
\hline $25-29$ Years & 146 & 37.2 \\
\hline $30-34$ Years & 62 & 15.8 \\
\hline$>34$ Years & 13 & 3.3 \\
\hline \multicolumn{3}{|l|}{ Educational status } \\
\hline No formal education & 56 & 14.2 \\
\hline Elementary school & 166 & 42.2 \\
\hline Secondary school & 116 & 29.5 \\
\hline Above secondary school & 55 & 14 \\
\hline \multicolumn{3}{|l|}{ Religion } \\
\hline Orthodox & 279 & 71.0 \\
\hline Muslim & 85 & 21.6 \\
\hline Protestant & 29 & 7.4 \\
\hline \multicolumn{3}{|l|}{ Ethnicity } \\
\hline Amhara & 195 & 49.6 \\
\hline Oromo & 82 & 20.9 \\
\hline Gurage & 100 & 25.4 \\
\hline Tigre & 16 & 4.1 \\
\hline \multicolumn{3}{|l|}{ Occupational status } \\
\hline Government employee & 22 & 5.6 \\
\hline Private employee & 106 & 27.0 \\
\hline Running personal business & 60 & 15.3 \\
\hline House wife & 189 & 48.1 \\
\hline Jobless & 16 & 4.1 \\
\hline \multicolumn{3}{|c|}{ Monthly income (Ethiopian birra } \\
\hline$<=500.00$ Birr & 116 & 29.5 \\
\hline$>500.00$ Birr & 277 & 70.5 \\
\hline
\end{tabular}

$\mathrm{a}_{1}$ USD $=20.05 \mathrm{ETB}$

the women reported history of still birth. Almost one fifth of the women $(71 ; 18.1 \%)$ had experienced abortion. Near to two thirds $(248 ; 63.1 \%)$ of the respondents reported that their pregnancy was planned (Table 2).

\section{Psychiatric history and substance use}

In considering the psychiatric characteristics 96 (24.4\%) of the participant reported a previous history of depression and $21(5.3 \%)$ of the women reported presence of history of depression in the family. Among the respondents 4 ( $1 \%)$ had used tobacco while 99 (25.2 \%) had used alcohol at least once in the last twelve months. The proportion of pregnant women who had used cannabis 
Table 2 Obstetric and clinical characteristics of pregnant women's attending Public health centers ANC clinic in Addis Ababa, April, $2012(n=393)$

\begin{tabular}{|c|c|c|c|}
\hline Explanatory variables & Categories & Frequency & Percentage \\
\hline \multirow[t]{3}{*}{ Trimester } & First trimester & 27 & 6.1 \\
\hline & Second trimester & 132 & 34.4 \\
\hline & Third trimester & 234 & 59.5 \\
\hline \multirow[t]{2}{*}{ Having previous pregnancy } & No & 191 & 48.6 \\
\hline & Yes & 202 & 51.4 \\
\hline \multirow{2}{*}{$\begin{array}{l}\text { Previous pregnancy } \\
\& \text { labor complication }\end{array}$} & No & 352 & 89.6 \\
\hline & Yes & 41 & 10.4 \\
\hline \multirow[t]{4}{*}{ Previous number of children } & 0 & 239 & 60.8 \\
\hline & 1 & 101 & 25.7 \\
\hline & 2 & 40 & 10.2 \\
\hline & $\geq 3$ & 15 & 3.4 \\
\hline \multirow[t]{2}{*}{ Previous history of still birth } & Yes & 11 & 2.8 \\
\hline & No & 382 & 97.2 \\
\hline \multirow[t]{2}{*}{ Previous history of abortion } & No & 321 & 81.9 \\
\hline & Yes & 72 & 18.1 \\
\hline \multirow[t]{2}{*}{ Type of abortion } & Spontaneous & 37 & 48.61 \\
\hline & Induced & 35 & 51.39 \\
\hline \multirow{2}{*}{$\begin{array}{l}\text { Is the current pregnancy } \\
\text { planned }\end{array}$} & No & 145 & 36.9 \\
\hline & Yes & 248 & 63.1 \\
\hline \multirow[t]{3}{*}{ Previous ANC follow up } & No follow up & 134 & 34.1 \\
\hline & Sometimes & 10 & 2.5 \\
\hline & Regular & 58 & 14.0 \\
\hline \multirow{2}{*}{$\begin{array}{l}\text { Current pregnancy } \\
\text { complication }\end{array}$} & Yes & 24 & 6.1 \\
\hline & No & 369 & 93.9 \\
\hline \multicolumn{4}{|l|}{ History of chronic illness } \\
\hline & Yes & 367 & 93.4 \\
\hline & No & 26 & 6.6 \\
\hline
\end{tabular}

and khat at least once in the last twelve months were 2 $(0.5 \%)$ and 7 (1.8\%), respectively.

\section{Prevalence of antenatal depression}

The internal consistency of EPDS tool was acceptable (Cronbach's $\alpha=0.77$ ). The prevalence of antenatal depression ( $\geq 13$ on EPDS score) was $24.94 \%$ (95\% CI: 20.85-29.30\%). The prevalence of antenatal depression among first trimester women was $5.1 \%$ while it was 27.6 and $67.3 \%$ among second and third trimester women respectively.

\section{Factors associated with antenatal depression (Logistic regression analysis)}

The following variables were not significantly associated with antenatal depression in the bivariate analysis: Trimester, having previous pregnancy, previous pregnancy
\& labor complication, number of ever born children, previous history of still birth, previous history of abortion, history of chronic illness, age of the respondent and substance use in the last 12 months. As shown in Table 3 marital status, educational level, planned pregnancy, partners' feeling about the pregnancy, fathers' support, community support, and history of depression were statistically associated with depression in the bivariate analysis. However unplanned pregnancy, pregnant women experienced lack of baby's father support, and previous history of depression were the associated factors with antenatal depression among pregnant women in the multivariable model.

As shown in Table 3 antenatal depression was significantly higher among women who had not planned their current pregnancy. Those women who had not planned their current pregnancy were 2.78 times more likely to have antenatal depression than those who had planned their pregnancy $[\mathrm{AOR}=2.78(95 \% \mathrm{CI}: 1.59-4.85)]$. Absence of support from baby's father was also associated with higher odds of having antenatal depression. Pregnant

Table 3 Factors associated with antenatal depression among pregnant women attending public health centers ANC clinic in Addis Ababa, April 2012. $(n=393)$

\begin{tabular}{|c|c|c|}
\hline Explanatory variables & $\operatorname{COR}(95 \% \mathrm{Cl})$ & AOR $(95 \% \mathrm{Cl})$ \\
\hline \multicolumn{3}{|l|}{ Current marital status } \\
\hline $\begin{array}{l}\text { Non married (Single, } \\
\text { divorced and widowed) }\end{array}$ & $4.734(2.394-9.361)$ & $1.799(0.728-4.441)$ \\
\hline Married & 1 & 1 \\
\hline \multicolumn{3}{|l|}{ Educational status } \\
\hline No formal education & $3.316(1.256-8.750)$ & $2.46(0.849-7.114)$ \\
\hline Elementary school & $2.625(1.108-6.221)$ & $2.0(0.783-5.11)$ \\
\hline Secondary school & $2.227(0.907-5.472)$ & $1.652(0.63-4.332)$ \\
\hline College and above & 1 & 1 \\
\hline \multicolumn{3}{|l|}{ Planned pregnancy } \\
\hline No & $3.901(2.418-6.292)$ & $2.779(1.594-4.846)$ \\
\hline Yes & 1 & 1 \\
\hline \multicolumn{3}{|c|}{ Partner's feeling on current pregnancy } \\
\hline Unhappy & $5.496(3.081-9.805)$ & $1.605(0.708-3.642)$ \\
\hline Happy & 1 & 1 \\
\hline \multicolumn{3}{|l|}{ Baby's fathers support } \\
\hline Poor & $3.680(2.266-6.002)$ & $1.89(1.064-3.358)$ \\
\hline Good & 1 & 1 \\
\hline \multicolumn{3}{|l|}{ Community's support } \\
\hline Poor & $2.107(1.074-4.136)$ & $0.819(0.370-1.814)$ \\
\hline Good & 1 & 1 \\
\hline \multicolumn{3}{|l|}{ History of depression } \\
\hline Yes & $3.347(2.036-5.503)$ & $2.569(1.475-4.475)$ \\
\hline No & 1 & 1 \\
\hline
\end{tabular}


women who experienced lack of support from the baby's father were $89 \%$ higher odds of having antenatal depression when compared with women who got support from the baby's father $[\mathrm{AOR}=1.89(95 \% \mathrm{CI}: 1.06-3.36)]$. History of depression was found one of the factors associated with antenatal depression. Those pregnant women who had previous history of depression were nearly three times at higher odds of having depression as compared to pregnant women who had no history of depression [AOR = 2.57(95 \% CI: 1.48-4.48 )]. Educational level, community's support and partner's feeling on the current pregnancy were not significantly associated with depression during pregnancy in the multivariable logistic regression model.

\section{Discussion}

This study showed that there was a high prevalence of antenatal depression among pregnant women who have ANC follows up at public Health centers in Addis Ababa. The finding showed that 24.94 \% (95 \% CI: 20.85-29.30) of the antenatal care attendee pregnant women had depression based on the EDPS. Many studies reported higher prevalence of antenatal depression such as $39.5 \%$ in Tanzania [11], $39 \%$ in two Cape Town peri-urban settlements [12] and $56 \%$ in Jamaica [34]. A relatively similar prevalence was reported from Brazil (20.2 \%) [11] and Rural Bangladesh (18 \%) [9]. The methodological differences between studies and different measurement tools might attribute to the difference in the prevalence of depression among these countries. The socio demographic and economic differences might also attribute for the difference in prevalence of antenatal depression between this study and the studies from other developing countries.

Antenatal depression was significantly higher among women who were not planned on their current pregnancy. Those women who were not planned on their current pregnancy were 2.58 times more likely to have antenatal depression than those pregnant women who had planned the pregnancy. This is possibly because pregnancy causes physical, psychological and hormonal changes [35] that is why pregnancy needs physical, psychological and financial preparation. A consistent finding was also reported from rural Southwestern Ethiopia [29]. Other supporting findings regarding the importance of planning pregnancy for prevention of antenatal depression were reported from different part of the world [13, 36-39]. Unintended pregnancy was found as risk factor perinatal mental disorders in women in low- and lower-middle-income countries [8]. However, a study done in two Cape Town peri-urban settlements did not found a significant association between unwanted pregnancy and antenatal depression [12].

Experiencing lack of baby's father support was found to be a statistically significant factor associated with depression during pregnancy. This is possibly because those women who receive partner's support during their pregnancy well empowered to deal with their pregnancy and their home responsibility. This finding agreed with many studies conducted in different countries $[8,9,12$, 33]. It is also possible that depressed women might feel that the support they receive is not sufficient.

A previous history of depression was a significant factor that associated with the development of antenatal depression. Those pregnant women might be more biologically vulnerable to depression, and the hormonal changes of pregnancy increase vulnerability to depression, or their psycho-social context may make them vulnerable to recurrent depression. This is also consistent with many other studies $[8,9,12,40,41]$.

The mental health services are not adequate in Ethiopia. However this study implicates that the problem of antenatal depression is rampant even in the capital of the country. This recalled the importance of integrating mental health services with maternal health program. In the context of low- and middle-income countries, designing both treatment and preventive interventions are important to reduce the burden of mental health problem. A systematic review study concluded that in low and middle income countries, the burden of common perinatal mental disorders can be reduced through mental health interventions delivered by supervised non-specialists [42].

This study has limitations. EDPS is not a diagnostic aid, it is a screening method. Making a diagnosis of antenatal depression based on EDPS scale without psychiatric examination is difficult. Women in the sample were recruited from Public Health Centers in Addis Ababa who attended during the study period. They might not be representative of all antenatal care clients, and the sample did not include pregnant women who did not attend for antenatal care and those attended ANC at private health institutions. Majority of public health center users in Addis Ababa are people from low socioeconomic status which question the representativeness of this study across all socioeconomic groups. The other limitation is that major life events and possible comorbid diagnosis such as HIV status, gender violence, anxiety or dysthymia were not assessed. The effect of nutritional status such as anemia was also not investigated in this study.

\section{Conclusion}

One quarter of the pregnant women attending Addis Ababa Public Health Centers ANC clinic were depressed based on the EPDS. Further examination of these pregnant women by a psychiatrist to confirm such diagnosis is recommended. Unplanned pregnancy, experiencing lack of baby's father support and previous history of 
depression were factors independently associated with antenatal depression.

Health care professionals need to enquire about the relevant risk factors as part of their overall assessment giving attention to those pregnant women who had unplanned pregnancy, who have poor partner support, and who had a previous history of depression. Promotion of family planning, male involvement in maternal health especially during pregnancy and integration of mental health service with existing maternal health care as well as strengthening the referral system among public health centers were the recommended interventions.

\section{Competing interests}

The authors declare that they have no competing interests.

\section{Author's contributions}

$A B$ conceived the study, supervised the data collection, analyzed and interpret the data, critically reviewed the manuscript. DH drafted the manuscript, assisted the data interpretation and critically reviewed the manuscript. Both authors read and approved the final manuscript.

\section{Acknowledgement}

We thank to university of Gondar and Amaneul Specialized Mental Hospital. We are also grateful to the study participants, data collectors and supervisors.

\section{Funding}

This study was funded by university of Gondar. The funder has no role in design, analysis, data interpretation and publication of the finding.

\section{Author details}

${ }^{1}$ Department of Nursing, College of Medicine and Health sciences, Madwalabu University, Bale Goba, Ethiopia. ${ }^{2}$ Department of Reproductive Health, College of Medicine and Health sciences, Bahir Dar University, P.Box 79, Bahir Dar, Ethiopia.

Received: 5 June 2015 Accepted: 26 October 2015

Published online: 30 October 2015

\section{References}

1. Pillay B, Cassimjee M. Anxiety and depression in an urban general practice. J Anxiety Depress. 2000;3(2):4-5.

2. World Health Organization (WHO). DEPRESSION: A Global Public Health Concern. 2012. Available at http://www.who.int/mental_health/ management/depression/who_paper_depression_wfmh_2012.pdf. Accessed May 11, 2012.

3. Evans J, Heron J, Francomb H, Oke S, Golding J. Cohort study of depressed mood during pregnancy and after childbirth. BMJ. 2001;323:257-60.

4. Fatoye FO, Adeyemi AB, Oladimeji B. Emotional distress and its correlates among Nigerian women in late pregnancy. J Obstet Gynecol. 2004;24:504-9.

5. Gotlib IH, Whiffen VE, Mount JH, Milne K, Cordy NI. Prevalence rates and demographic characteristics associated with depression in pregnancy and the postpartum. J Consult Clin Psychol. 1989;57(2):269-74.

6. O'Keane V, Marsh MS. Depression during pregnancy. BMJ. 2007;334:1003-5.

7. Bennett HA, Einarson A, Taddio A, Koren G, Einarson TR. Prevalence of depression during pregnancy: systematic review. Obstet Gynecol. 2004;103(4):698-709.

8. Fisher J, Mello MC, Patel V, Rahman A, Tran T, Holton S, et al. Prevalence and determinants of common perinatal mental disorders in women in low- and lower-middle-income countries: a systematic review. Bull World Health Organ. 2012;90(2):139G-49G.

9. Nasreen HE, Kabir ZN, Forsell Y, Edhborg M. Prevalence and associated factors of depressive and anxiety symptoms during pregnancy: a population based study in rural bangladesh. BMC Womens Health. 2011;11:22.

10. Rahman A, lqbal Z, Harrington R. Life events, social support and depression in childbirth: perspectives from a rural community in the developing world. Psychol Med. 2003;33:1161-7.
11. Faisal-Cury A, Menezes P, Araya R, Zugaib M. Common mental disorders during pregnancy: prevalence and associated factors among low-income women in São Paulo, Brazil. Arch Women Ment Health. 2009;120:335-43.

12. Hartley M, Tomlinson M, Greco E, Comulada WS, Stewart J, Roux I, et al. Depressed mood in pregnancy: prevalence and correlates in two Cape Town peri-urban settlements. Reprod Health. 2011;8:9.

13. Manikkam L, Burns JK. Antenatal depression and its risk factors: an urban prevalence study in KwaZulu-Natal. S Afr Med J. 2012;102(12):940-4.

14. Kaaya SF, Mbwambo JK, Kilonzo GP, Van Den Borne H, Leshabari MT, Fawzi $M C$, et al. Socio-economic and partner relationship factors associated with antenatal depressive morbidity among pregnant women in Dar es Salaam, Tanzania. Tanzan J Health Res. 2010;12(1):23-35.

15. Alder J, Fink V, Bitzer J, Hosli I, Holzgreve W. Depression and anxiety during pregnancy: a risk factor for obstetric, fetal and neonatal outcome? A critical review of the literature. J Matern Fetal Med. 2007;20:189-209.

16. Kazi A, Fatmi Z, Hatcher J, Kadir MM, Niaz U, Wasserman GA. Social environments and depression among pregnant women in urban areas of Pakistan: Importance of social relations. Soc Sci Med. 2006;63:1466-76.

17. Hart R, McMahon CA. Mood state and psychological adjustment to pregnancy. Arch Womens Ment Health. 2006;9:329-37.

18. Sawyer A, Ayers S, Smith H. Pre and postnatal psychological well being in Africa: a systematic review. J Affect Disord. 2010;123(1-3):17-29.

19. Koubovec D, Geerts L, Odendaal HJ, Stein DJ, Vythilingum B. Effects of psychological stress on fetal development and pregnancy outcome. Curr Psychiatry Rep. 2005;7:274-80.

20. Rahman A, Bunn J, Lovel H, Creed F. Association between antenatal depression and low birth weight in a developing country. Acta Psychiatr Scand. 2007;115:481-6

21. Grote NK, Bridge JA, Gavin AR, Melville JL, lyengar S, Katon WJ. A metaanalysis of depression during pregnancy and the risk of preterm birth, low birth weight, and intrauterine growth restriction. Arch Gen Psychiatry. 2010;67(10):1012-24.

22. Stewart RC, Umar E, Kauye F, Bunn J, Vokhiwa M, Fitzgerald M, et al. Maternal common mental disorder and infant growth-a cross-sectional study from Malawi. Matern Child Nutr. 2008;4(3):209-19.

23. Rondó PHC, Ferreira RF, Nogueira F, Ribeiro MCN, Lobert N, Artes R. Maternal psychological stress and distress as predictors of low birth weight, prematurity and intrauterine growth retardation. Eur J Clin Nutr. 2003;57:266-72.

24. Evans J, Heron J, Patel RR, Wiles N. Depressive symptoms during pregnancy and low birth weight at term. Br J Psychiatry. 2007;191:84-5.

25. Wisner KL, Sit DK, Hanusa BH, Moses-Kolko EL, Bogen DL, Hunker DF, et al. Major depression and antidepressant treatment: impact on pregnancy and neonatal outcomes. Am J Psychiatry. 2009;166(5):557-66.

26. Field T, Diego M, Hernandez-Reif M. Prenatal depression effects on the fetus and newborn: a review. Infant Behav Dev. 2006;29(3):445-55.

27. Hanlon C, Medhin G, Alem A, Araya M, Abdulahi A, Hughes M, et al. Detecting perinatal common mental disorders in Ethiopia: validation of the self-reporting questionnaire and Edinburgh Postnatal Depression Scale. J Affect Disord. 2008;108:251-62.

28. Tesfaye M, Hanlon C, Wondimagegn D, Alem A. Detecting postnatal common mental disorders in Addis Ababa, Ethiopia: validation of the Edinburgh Postnatal Depression Scale and Kessler Scales. J Affect Disord. 2010;122(1-2):102-8.

29. Dibaba Y, Fantahun M, Hindin MJ. The association of unwanted pregnancy and social support with depressive symptoms in pregnancy: evidence from rural Southwestern Ethiopia. BMC Pregnancy Childbirth. 2013;13:135.

30. Central Statistics Agency (Ethiopia). Summary and Statistical Report of the 2007 Population and Housing Census, Population Census Commission. Addis Ababa: Federal Democratic Republic of Ethiopia; 2007.

31. Murray D, Cox JL. Screening for depression during pregnancy with the Edinburgh Postnatal Depression Scale (EPDS). J Reprod Infant Psychol. 1990;8:99-106.

32. Gibson J, McKenzie-McHarg K, Shakespeare J, Price J, Gray R. A systematic review of studies validating the Edinburgh Postnatal Depression Scale in antepartum and postpartum women. Acta Psychiatr Scand. 2009;119:350-64.

33. Senturk V, Abas M, Berksun O, Stewart R. Social support and antenatal depression in extended and nuclear family environments in Turkey: a cross-sectional survey. BMC Psychiatry. 2011;11:48. 
34. Wissart J, Parshad O, Kulkarni S. Prevalence of pre- and postpartum depression in Jamaican women. BMC Pregnancy Childbirth. 2005;5:15.

35. Hickey CA, Cliver S, Goldenberg RL, McNeal SF, Hoffman HJ. Relationship of psychosocial status to low prenatal weight gain among non-obese black and white women delivering at term. Obstet Gynaecol. 1995;86:177-83.

36. Karmaliani R, Asad N, Bann C, Moss N, Mcclure EM, Pasha O, et al. Prevalence of anxiety, depression and associated factors among pregnant women of Hyderabad, Pakistan. Int J Soc Psychiatry. 2009;55:414-24.

37. Silva RA, Jansen K, Souza LDM, Moraes IGS, Tomasi E, Silva Gdel G, et al. Depression during pregnancy in the Brazilian public health care system. Rev Bras Psiquiatr. 2010;32(2):139-44.

38. Rich-Edwards JW, Kleinman K, Abrams A, Harlow BL, Thomas J, McLaughlin $\mathrm{TJ}$, et al. Sociodemographic predictors of antenatal and postpartum depressive symptoms among women in a medical group practice. J Epidemiol Community Health. 2006;60:221-7.

39. Bunevicius R, Kusminskas L, Bunevicius A, Nadisaukiene RJ, Jureniene K, Pop VJ. Psychosocial risk factors for depression during pregnancy. Acta Obstet Gynecol Scand. 2009;88(5):599-605.

40. Johanson R, Chapman G, Murray D, Johnson I, Cox J. The North Staffordshire Maternity Hospital prospective study of pregnancy-associated depression. J Psychosom Obstet Gynaecol. 2000;21(2):93-7.

41. Dayan J, Creveuil C, Dreyfus M, Herlicoviez M, Baleyte J-M, O'Keane V. Developmental model of depression apply to prenatal depression: role of present and past life events, past emotional disorders and pregnancy stress. PLoS One. 2010;5(9):e12942.

42. Rahman A, Fisher J, Bower P, Luchters S, Tran T, Yasamy MT, et al. Interventions for common perinatal mental disorders in women in low-and middle-income countries: a systematic review and meta-analysis. Bull World Health Organ. 2013;91:593-601.

\section{Submit your next manuscript to BioMed Central and take full advantage of:}

- Convenient online submission

- Thorough peer review

- No space constraints or color figure charges

- Immediate publication on acceptance

- Inclusion in PubMed, CAS, Scopus and Google Scholar

- Research which is freely available for redistribution 